\title{
Isotopic Analysis of Sugarcane/Petroleum Polyethylene Blends: A Perspective on the Application of Stable Isotope Method $\left(\delta^{13} \mathrm{C}\right)$
}

\author{
Victor H. J. M. dos Santos ${ }^{\circledR a}$ and Luiz F. Rodrigues ${ }^{(*, a}$ \\ ${ }^{a}$ Instituto do Petróleo e dos Recursos Naturais, Pontifícia Universidade Católica do Rio Grande do Sul, \\ Avenida Ipiranga, 6681, Prédio 96J, Partenon, 90619-900 Porto Alegre-RS, Brazil
}

\begin{abstract}
In the present work, we propose the application of stable isotope analysis $\left(\delta^{13} \mathrm{C}\right)$ as an auxiliary tool for the inspection of sugarcane/petroleum polyethylene blends. Our results are supported from the analysis of selected samples by accelerator mass spectrometry $\left({ }^{14} \mathrm{C}\right.$-AMS $)$. From the results, it was concluded that the $\delta^{13} \mathrm{C}$ method is suitable to discriminate samples derived from sugarcane, petroleum, or its blends. It was also noted that both regression models $\left(\delta^{13} \mathrm{C}\right.$ method and the $\delta^{13} \mathrm{C} v{ }^{14} \mathrm{C}$-AMS regression) presents potential to estimate the bio-based content; however, future work should focus on validating these models. From the screening model, developed with $\delta^{13} \mathrm{C}$ data, $33.33 \%$ of the samples were highlighted as suspected of being out of specification. Thus, the screening method can identify samples most likely to be out of specification and reduce the demand for inspection of biogenic content following the ASTM D6866 standard $\left({ }^{14} \mathrm{C}-\mathrm{AMS}\right)$.
\end{abstract}

Keywords: bio-based polymer, polymer blends, IRMS, stable isotope, radiocarbon, ${ }^{14} \mathrm{C}$ AMS

\section{Introduction}

Plastics are ubiquitous materials with favorable mass, energy, and financial balances. ${ }^{1,2}$ Petro-based polymers comprise most of the global market, and among petrochemical commercialized resins, polypropylene (PP, $19.1 \%$ ), low density polyethylene (LDPE/LLDPE, 17.3\%), high density polyethylene (HDPE, 12.1\%), polyvinyl chloride (PVC, 10.1\%), polyethylene terephthalate (PET, $7.1 \%$ ), and polystyrene (PS, 6.9\%) account for $72.60 \%$ of the trade volume. ${ }^{3}$ Among the polymeric resins, polyethylene is especially important, since all of its different forms (HDPE, LDPE, and LLDPE) account for $29.4 \%$ of the plastics global market. ${ }^{3,4}$ Their versatility, high relationship between their properties and weight, and elevated chemical stability, justify their importance to the petrochemical industry. ${ }^{4}$ Plastic materials constitute an important environmental pollution source and contribute significantly to the human ecological footprint. ${ }^{5,6}$ Thus, to reduce human pressure on the environment and dependence on fossil raw materials, biobased polymers have entered the market and have gradually increased their importance in the global share. While the environmental aspects should be addressed by Life Cycle Assessment (LCA) studies, the reduction of fossil resource consumption is more easily evaluated.

*e-mail: frederico.rodrigues@pucrs.br
According to the American Society for Testing and Materials (ASTM), biogenic or bio-based content refers to the relative contribution of organic and inorganic carbon derived from renewable origin. ${ }^{7}$ Bio-based plastics are materials derived from biomass resources and are generally produced from bio-derivatives, including cellulose, starch, triglycerides, and sugar. ${ }^{4,8-11}$ In this context, the $\mathrm{CO}_{2}$ recycling to biomass production during plant growth is the key factor to ensure material renewability. Some examples of successful bio-based polymers are polylactic acid (PLA), partially bio-based polyethylene terephthalate (bio-based PET), and "green polyethylene" (bio-based PE). ${ }^{12}$ These three resins composed $46.30 \%$ of the 2017 bioplastics global production, with a relative contribution of $26.3 \%$ for partially bio-based PET, $10.3 \%$ for PLA, and 9.7\% for bio-based PE. ${ }^{13}$ The main advantage of partially bio-based PET and bio-based PE is that they present exactly the same relevant properties of their petro-based counterparts. ${ }^{4}$ This means that there is no need to make significant adaptations to the second and third generation petrochemical processing industries.

In 2007, a petrochemical company launched the operation of a pilot plant to produce ethylene from catalytic dehydration of ethanol derived from sugarcane, which is used for the production of bio-based PE with exactly the same performance of petrochemical PE. ${ }^{4,14}$ In Figure 1, the differences between petro-based and bio-based PE are 
presented in a simplified scheme, summarized from several LCA studies. ${ }^{12,15-19}$

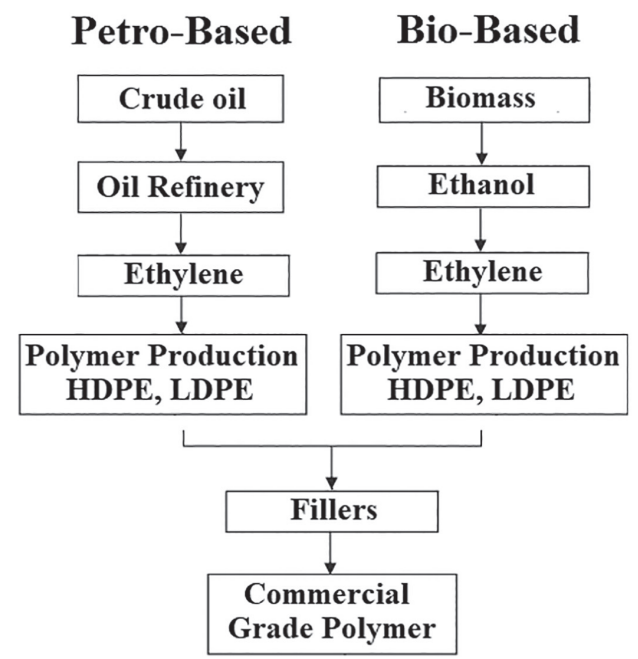

Figure 1. Simplified scheme for petro-based and bio-based polyethylene production routes.

If the similarity between the polyethylene derived from sugarcane and petroleum represents an advantage for producers and stakeholders, the same characteristic represents a challenge for the accreditation of declared biogenic content, as far as carrying out material inspections and conducting product tracing. Thus, to validate the declared biogenic content of the bio-based and partially biobased polymers, widely recognized international standards should be applied. ${ }^{20}$ ASTM D6866 ${ }^{7}$ is the most recognized standardized method for bio-based content accreditation and is defined as the fraction of biogenic carbon mass in the material. ${ }^{7,21}$ Therefore, the certification of the declared biobased content is of great importance for the stakeholder's protection, whether they are producers or end consumers.

In the literature, several papers ${ }^{2,10,20-26}$ focus on the ${ }^{14} \mathrm{C}$ experimental protocol and on the assessment of bio-based content in polymers, polymer blends, and composite materials. However, the ${ }^{14} \mathrm{C}$ assessment by accelerator mass spectrometry (AMS) is a laborious, time consuming, and expensive method, even with available AMS systems becoming much more compact than before. ${ }^{5,20,27}$ Since it is impossible to maintain an AMS only with the bio-based carbon content analysis demand, the application of faster and cheaper auxiliary methods can help in consumer protection for product quality control or as sample screening methods in the product inspection chain. ${ }^{5,20}$ Among the technological options, isotope ratio mass spectrometry (IRMS) appears to be the technique with the greatest immediate potential. The ${ }^{13} \mathrm{C} /{ }^{12} \mathrm{C}$ isotope ratio, normally denoted as $\delta^{13} \mathrm{C}$, presents potential for the evaluation of material identity and the differentiation of carbon sources in an organic matrix. ${ }^{28-31}$
The stable isotope method has already been applied for the analysis of packaging tapes, grip-seal plastic bags, cling film, petro-based commodity polymers, and biobased polymers. ${ }^{5,28,32-35}$ In these studies, the main research objectives have been to perform the forensic evaluation of plastic materials, to characterize polymer waste, and to determine the base/origin of the plastic material. $5,28,32-34,36$

While there is a consensus that bio-based products have similar functions and performances as conventional petro-based materials, biomass-derived plastic currently has a higher production cost and consequently a higher market value. Thus, many companies opt for performing the partial replacement of conventional plastics with bio-based materials, resulting in commercial blends with varying percentages of bio-based/petro-based carbon. Because of this, the accreditation of the bio-based fraction in polymeric blends is a key issue for quality control purposes and for consumer protection, as consumers can guide their consumption preferences based on the company's environmental engagement. ${ }^{14,21,22}$ However, the increase in the market for bio-based materials was not followed by the dissemination of quality control laboratories with technology and certification to guarantee the information stated on the products labels. Thus, the high cost of carrying out the verification of biogenic content and the low availability of certified centers to perform bio-based carbon accreditation following ASTM D6866 7 are issues that currently need to be overcome.

Nowadays, Brazil has a single ${ }^{14} \mathrm{C}$-AMS equipment, which meets the demands of research and development in different sectors. ${ }^{37}$ Considering that it is impossible to carry out the quality control of bio-based polymers in only one certified center, many companies validate the biogenic content in its products in laboratories located in other countries. Furthermore, the availability of only one certified center in Brazil represents a risk for the quality assurance of bio-based materials and for the use of "environmentally friendly" labels, the sector being extremely susceptible to fraud. Thus, the development of auxiliary methodologies can help to establish an inspection chain, significantly reducing the number of samples that must be sent for confirmation of biogenic content.

Because of the evident difficulties of carrying out the inspection of bio-based materials, the present work proposes the application of the carbon stable isotope method $\left(\delta^{13} \mathrm{C}\right)$ for the analysis of sugarcane/petroleum polyethylene blends available in the Brazilian market. Thus, the main objectives of this work are to assess the potential and limitations of $\delta^{13} \mathrm{C}$ data for: ( $i$ ) discriminate the origins of the samples, (ii) calibrate regression models to estimate the biogenic content of sugarcane/petroleum 
polyethylene blends and (iii) develop a screening model to identify samples most likely to be out of specification. In this context, the proposed methods can assist in the quality control process, significantly reducing the number of samples that must be sent for inspection of the biogenic content following the ASTM D6866 standard $\left({ }^{14} \mathrm{C}-\mathrm{AMS}\right) .{ }^{7}$

\section{Experimental}

In the present work, samples of sugarcane/petroleum polyethylene blends available in the Brazilian market were analyzed using IRMS to determine the $\delta^{13} \mathrm{C}$ isotope ratios. All polymer blends were obtained from the Brazilian market, including products such as packaging materials, plastic bags, and ornamental products. The PE materials came from several suppliers and company names are omitted in the present work. In addition to PE polymer blends, bio-based polymers (natural rubber-NR and PLA), partially bio-based PET, biopolymer raw materials (sugarcane sucrose and sugarcane ethanol), and other ubiquitous polymeric materials (HDPE, LDPE, LLDPE, PET, PVC, PP, and PS) were analyzed to verify their isotopic values. These polymeric materials comprised second-generation petrochemical derivatives (pellets and rubber strips) and manufactured products (e.g., packaging, plastic bags, bottles, plastic pipes, and polymer films).

To validate our approach, six selected PE samples (STD-1, M-3, M-6, M-11, M-12, and M-14) were sent for external ${ }^{14} \mathrm{C}$-AMS analysis following the ASTM D6866 standard. ${ }^{7}$

Materials

The materials used in this work were COM-CAT combustion accelerator (LECO Corporation, St. Joseph, USA), laboratory grade $\mathrm{CO}_{2} 4.5$ (Air Liquide, São Paulo, Brazil), helium 5.0 (Air Products, São Paulo, Brazil), sugarcane ethanol (Química Moderna, São Paulo, Brazil), sugarcane sucrose (local suppliers, Porto Alegre, Brazil), bio-based PE pellets (Braskem, Triunfo, Brazil), petrobased PE pellets (Braskem, Triunfo, Brazil), partially biobased PET (Coca-Cola plant bottle, Porto Alegre, Brazil), and natural rubber (Tipler, São Leopoldo, Brazil). Other plastic materials (HDPE, LDPE, LLDPE, PET, PP, PS, and PVC) were collected in the local market (Porto Alegre, Brazil) and are widely available.

The development of sugarcane-based polyethylene resulted in the development of a "environmentally-friendly" label, based on bio-based content accreditation through ASTM D6866. ${ }^{38}$ The sugarcane/petroleum PE polymer blends are found in the Brazilian market, generally comprising packaging or ornamental materials, and have declared biogenic contents over 51\%. ${ }^{39}$

\section{Elemental analysis}

The stable isotope analysis method was previously reported by our research group ${ }^{40,41}$ and adapts the sample combustion in a conventional elemental analyzer (EA) (Leco SC-632), followed by $\delta^{13} \mathrm{C}$ analysis in an IRMS from Thermo Fisher Scientific. Although the EA was not directly coupled to IRMS, due to the lack of compatibility among the equipment, this combustion scheme has already been applied in other studies with acceptable values of standard deviations and isotopic fractionation. ${ }^{40,41}$

Before analysis, the polymer samples were ground and weighed on a ceramic platform and a catalyst was added to ensure complete combustion of the material. After the complete conversion of the sample carbon fraction into $\mathrm{CO}_{2}$, the exhaust gas was collected in special quartz vials $(500 \mathrm{~mL})$, previously flushed with helium, and coupled to the EA purge valve. To homogenize the sample, the exhaust gas was allowed to pass through the quartz vial for $50 \mathrm{~s}$ and then a $50-\mu \mathrm{L}$ aliquot was withdrawn through a rubber septum and injected into the gas chromatograph coupled to the isotope ratio mass spectrometer (GC/IRMS) to separate the gas components and avoid isobaric interferences. The encoded sample results represent the average of three independent polymer batch combustions (one combustion per batch) of materials with the same technical specifications (including color). Each of the collected quartz vials were analyzed in duplicate in order to ensure the reproducibility.

\section{Stable isotope ratio analysis $\left(\delta^{13} \mathrm{C}\right.$-IRMS)}

The stable carbon isotope $\left(\delta^{13} \mathrm{C}\right)$ ratios were determined with a gas chromatograph (trace GC) coupled to an IRMS (DELTAV Plus) via a combustion interface (GC IsoLink). The GC was equipped with a Carboxen Plot 1006 capillary column (30 m length, $0.53 \mathrm{~mm}$ inner diameter) and used helium $\left(1.5 \mathrm{~mL} \mathrm{~min}^{-1}\right)$ as a carrier gas. The calibration, validation, quality control and uncertainty estimation were conducted following the recommendations of the Forensic Isotope Ratio Mass Spectrometry (FIRMS) Network. ${ }^{42}$ The stable isotope results are expressed in per mille units (\%o) and were calculated using equation 1 . The $\delta^{13} \mathrm{C}$ values are given as relative values in the Vienna Pee Dee Belemnite (VPDB) scale.

$\delta{ }^{13} \mathrm{C}_{\text {sample }}=\frac{\left({ }^{13} \mathrm{C} /{ }^{12} \mathrm{C}\right)_{\text {sample }}-\left({ }^{13} \mathrm{C} /{ }^{12} \mathrm{C}\right)_{\text {standard }}}{\left({ }^{13} \mathrm{C} /{ }^{12} \mathrm{C}\right)_{\text {standard }}} \times 1000$ 
In the present work, the recognized $\mathrm{CH}_{4}$ standard T-ISO2 $\left(\delta^{13} \mathrm{C}-38.3 \pm 0.2 \%\right.$ ) from Isometric Instruments, (Victoria, Canada) was applied to calibrate the inhouse standard (laboratory grade $\mathrm{CO}_{2}$ ) and the working standards: $(i)$ petro-based (STD-1) and (ii) sugarcanebased (STD-2 and STD-3) polyethylene. To date, there are no recognized "authentic" samples of bio-based polyethylene that can be used as a primary standard. Thus, as adopted by Santos et al. ${ }^{37}$ the raw polyethylene pellets (granules) supplied by a local petrochemical company (STD-1, STD-2, and STD-3) were considered as primary material of petro-based (STD-1) and sugarcane-based (STD-2 and STD-3) polyethylene.

In the calibration process, each of the standards (laboratory grade $\mathrm{CO}_{2}$, STD-1, STD-2 and STD-3) were analyzed 10 times against T-ISO2, to ensure the reliability of the isotopic value. Then, the $\delta^{13} \mathrm{C}$ of the samples was calculated against the laboratory grade $\mathrm{CO}_{2}\left(\delta^{13} \mathrm{C}=-32.85 \pm 0.2 \%\right.$ o introduced into the mass detector directly through an open split. Furthermore, the reproducibility of the measurements was guaranteed from the periodic analysis of T-ISO2 $\left(\delta^{13} \mathrm{C}=-38.3 \pm 0.2 \% \circ\right), \mathrm{STD}-1$ $\left(\delta^{13} \mathrm{C}=-30.43 \pm 0.23 \%\right.$ ), $\mathrm{STD}-2\left(\delta^{13} \mathrm{C}=-12.55 \pm 0.24 \%\right.$ $)$ and STD-3 $\left(\delta^{13} \mathrm{C}=-12.96 \pm 0.24 \%\right.$ o $)$ intercalated within the sample batch.

\section{Radiocarbon analysis $\left(\Delta^{14} \mathrm{C}-\mathrm{AMS}\right)$}

The $\left({ }^{14} \mathrm{C} /{ }^{12} \mathrm{C}\right)$ carbon isotope ratios were measured by AMS and analyzed at the Beta Analytic radiocarbon dating lab following ASTM D6866 standard. ${ }^{7}$ The percentage of modern carbon (pMC) was calculated from the sample ${ }^{14} \mathrm{C}$ content against the reference standard (NIST 4990C), and the bio-based content was estimated using an adjustment factor for the current ${ }^{14} \mathrm{C}$ signature of atmospheric carbon

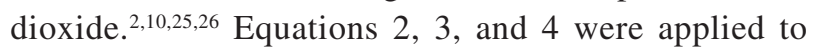
calculate the $\Delta^{14} \mathrm{C}$ isotope ratio, sample $\mathrm{pMC}$, and biogenic carbon fraction of the polyethylene samples, respectively. ${ }^{7}$ The "A" parameter (equation 2) denotes the ratios of ${ }^{14} \mathrm{C}$ to ${ }^{12} \mathrm{C}$ for samples and reference, and the adjustment factor (0.98) applied to calculate the biobased content (equation 4) was necessary to correct the post-1950 nuclear explosion ${ }^{14} \mathrm{C}$ injection into the atmosphere and is periodically reviewed by ASTM and other reference standards. ${ }^{7}$

$$
\begin{aligned}
& \Delta^{14} \mathrm{C}(\% \mathrm{o})=\frac{{ }^{14} \mathrm{~A}_{\text {sample }}-{ }^{14} \mathrm{~A}_{\text {reference }}}{{ }^{14} \mathrm{~A}_{\text {reference }}} \times 1000 \\
& \operatorname{pMC}(\%)=\left(\frac{\Delta^{14} \mathrm{C}}{1000}+1\right) \times 100
\end{aligned}
$$

Bio - based carbon ratio $(\%)=\mathrm{pMC} \times 0.98$
In the present work, six samples (STD-1, M-3, M-6, M-11, M-12, and M-14) were sent for external analysis by ${ }^{14} \mathrm{C}$-AMS to estimate the biogenic content based on ASTM D6866 standard. These samples cover a wide range of stable isotope data $\left(\delta^{13} \mathrm{C}\right.$ from -30.43 to $-13.60 \%$ ) and were applied to calibrate the $\delta^{13} \mathrm{C}$ method and the $\delta^{13} \mathrm{C} v s{ }^{14} \mathrm{C}$-AMS regression.

\section{Bio-based content estimation}

\section{$\delta^{13} \mathrm{C}$ method}

The bio-based content estimation was performed based on the $\delta^{13} \mathrm{C}$ values of petro-based $\mathrm{PE}$ and sugarcane-based $\mathrm{PE}$, as well as on the mass fraction of each resin in the polymer blends. Then, the equation 5 was adapted for the present case and did not require any adjustment factor, since the carbon elemental percentages in both PE resins were equivalent. ${ }^{43,44}$

$\delta^{13} \mathrm{C}_{\text {blend }}=\left[\left(1-\mathrm{w}_{\text {bio }}\right) \times \delta^{13} \mathrm{C}_{\text {petro }}\right]+\left(\mathrm{w}_{\text {bio }} \times \delta^{13} \mathrm{C}_{\text {bio }}\right)$

where, $w$ is the mass fraction and $\delta^{13} \mathrm{C}$ is the stable isotope value. This equation can also be presented as follows (equation 6):

$\delta^{13} \mathrm{C}_{\text {blend }}=\delta^{13} \mathrm{C}_{\text {petro }}+\left(\mathrm{w}_{\text {bio }} \times \delta^{13} \mathrm{C}_{\text {bio }}\right)-\left(\mathrm{w}_{\text {bio }} \times \delta^{13} \mathrm{C}_{\text {petro }}\right)$

In the present work, a regression model $\left(\delta^{13} \mathrm{C}\right.$ method $)$ was calibrated to estimate the biogenic content of sugarcane/petroleum polyethylene blends based on the $\delta^{13} \mathrm{C}$ data of petro-based standard (STD-1) and sugarcane-based sample (M-3). To ensure model reliability, the biogenic content of the STD-1 and M-3 were confirmed by the ${ }^{14} \mathrm{C}$-AMS, following the ASTM D6866 standard. ${ }^{7}$ The M-3 isotope data replace the $\delta^{13} C_{\text {bio }}$ equation term, while the STD-1 isotope data replace the $\delta^{13} C_{\text {petro }}$ term. The results of the $\delta^{13} \mathrm{C}$ method were compared with those obtained by the $\delta^{13} \mathrm{C} v s{ }^{14} \mathrm{C}$-AMS regression and the potential and limitations of their use to estimate the biogenic content of sugarcane/petroleum polyethylene blends were discussed.

Furthermore, a screening method was proposed combining: (i) the projection of the $\delta^{13} \mathrm{C}$ data of sugarcane/ petroleum polyethylene blends against the biogenic content declared on the product labels and (ii) the delimitation of a specification zone, considering the wide natural variation of the stable isotope value of derivatives of petroleum and $\mathrm{C}_{4}$ plants. The application domain of the screening model takes into account that the minimum content of sugarcane-based PE $(\geq 51 \%)$ is necessary for the use of "environmentally-friendly" label. ${ }^{37,39,45}$ Thus, the specification zone is delimited from the projection of 
the minimum and maximum regression line on the graph, defining the range of stable isotope value $\left(\delta^{13} \mathrm{C}\right)$ that the sugarcane/petroleum polyethylene blends (from 50 to $100 \%$ ) could present. The limits (minimum and maximum) were estimated based on equation 6 , considering the natural isotopic variation of $\mathrm{C}_{4}$ plants (from -10.0 to $-14.0 \%$ ) and crude oil (from -23.3 to $-32.5 \%$ o). ${ }^{46,47}$ Thus, by replacing the $\delta^{13} \mathrm{C}_{\text {perro }}$ and $\delta^{13} \mathrm{C}_{\text {bio }}$ terms of equation 6 with the isotope values from the literature, it is possible to estimate the minimum and maximum biogenic content expected for an unknown sample. The minimum content can be obtained by replacing the $\delta^{13} \mathrm{C}_{\text {petro }}$ and $\delta^{13} \mathrm{C}_{\text {bio }}$ terms with $-23.3 \%$ o $\left(\delta^{13} \mathrm{C}_{\text {petro }}\right)$ and $-10.0 \%$ o $\left(\delta^{13} \mathrm{C}_{\text {bio }}\right)$, while the maximum content can be obtained by replacing those terms with $-32.5 \%$ o $\left(\delta^{13} \mathrm{C}_{\text {petro }}\right)$ and $-14.0 \%$ o $\left(\delta^{13} \mathrm{C}_{\text {bio }}\right)$.

When considering the wide range of isotopic variation, the screening model can identify samples that present a notable deviation in biogenic content in relation to declared value on the product label. Thus, the possibility of false positives and negatives is reduced and the usefulness of the proposed model for sample screening is improved. The stable carbon isotope method does not replace accreditation in accordance with ASTM D6866; ${ }^{7}$ however, the potential and limitations of its use as a screening tool were discussed.

\section{$\delta^{13} \mathrm{C}$ vs ${ }^{14} \mathrm{C}$-AMS regression}

The $\delta^{13} \mathrm{C}$ data can also be applied to estimate the biogenic content of PE blends by linear regression of $\delta^{13} \mathrm{C}$ $v s{ }^{14} \mathrm{C}$-AMS. The model calibration was performed by using six points (STD-1, M-3, M-6, M-11, M-12, and M-14), covering the range between 0 and $98 \%$ of bio-based carbon percentage and stable isotope data $\left(\delta^{13} \mathrm{C}\right)$ from -30.43 to $-13.60 \%$. The linear regression follows equation 7 , with the predictor variable input $\left(\delta^{13} \mathrm{C}\right)$ in per mille units $(\% \circ)$ and the predicted variable $\left({ }^{14} \mathrm{C}\right.$-AMS $)$ expressed as biobased content (\%). In equation 7, the parameter "a" represents the slope and the parameter "b" represents the Y-intercept term.

Bio-based control $=\mathrm{a} \times \delta^{13} \mathrm{C}+\mathrm{b}$

The present method directly relates the $\delta^{13} \mathrm{C}$ data with the biogenic content estimated by ${ }^{14} \mathrm{C}$-AMS. Thus, the biogenic content of sugarcane/petroleum polyethylene blends can be estimated with reasonable reliability, since bio-based content data accredited using an international standard has been applied (ASTM D6866). ${ }^{7}$ The $\delta^{13} \mathrm{C} v s{ }^{14} \mathrm{C}$-AMS regression should include a considerable number of calibration points, covering the model's application domain and undergo periodic revalidations. The results of the $\delta^{13} \mathrm{C} v s{ }^{14} \mathrm{C}$-AMS regression were compared with those obtained by the $\delta^{13} \mathrm{C}$ method and the potential and limitations of their use to estimate the biogenic content of sugarcane/petroleum polyethylene blends were discussed.

\section{Results and Discussion}

\section{Discrimination of origin of plastics $\left(\delta^{13} \mathrm{C}\right)$}

Samples of sugarcane/petroleum PE blends available in the Brazilian market were analyzed to determine the $\delta^{13} \mathrm{C}$ isotope ratio. In addition to the polymer blends, bio-based polymers (NR and PLA), partially bio-based PET, biopolymer raw materials (sugarcane sucrose and sugarcane ethanol), and other commodity plastics, including HDPE, LDPE, LLDPE, PET, PVC, PP, and PS were analyzed to verify their isotopic values. Table 1 summarizes the $\delta^{13} \mathrm{C}$ results and provides a brief description of their characteristics and bio-based content, retrieved from the product label or assumed from the conventional production route. From Table 1, it is possible to observe a wide range of isotopic values, ranging from -30.43 to $-10.34 \%$, and the following results were observed:

(i) Raw materials (RM): the isotopic signatures of the raw materials used for the production of sugarcanebased PE, sucrose (RM-1 $=-10.68 \%$ ) and ethanol $(\mathrm{RM}-2=-11.34 \%$ ) , had typical carbon isotopic values for products derived from $\mathrm{C}_{4}$ plants. ${ }^{48-50}$

(ii) Bio-based polymers (BB): while the $\mathrm{C}_{4}$ bio-based polymers analyzed were composed of PLA samples, BB-1 $(-10.34 \% 0)$ and BB-2 $(-10.97 \% \circ)$, and HDPE samples, STD-2 (-12.55\%o), STD-3 (-12.96\%o), and BB-3 $\left(-13.41 \%\right.$ ) , the $\mathrm{C}_{3}$ bio-based polymers were composed of a natural rubber sample BB-4 (-27.72\%o). The isotopic signatures of all the bio-based polymers were within the expected range for their classes.

(iii) Polymer blends (M): the polymer blends were composed of sugarcane/petroleum PE blends, having isotopic ranges between -22.95 and $-12.97 \%$. In addition, the bio-based PE/petro-based PET blend M-13 (-19.62\%o) and the partially bio-based PET M-15 (-24.16\%o), prepared using the bio-based ethylene glycol, also compose the polymer blends set. Thus, the M-1 to M- 15 samples presents intermediate isotopic signatures, with $\delta^{13} \mathrm{C}$ between biobased and petro-based classes.

(iv) Petro-based polymers (PB): the petro-based materials had isotopic values ranging from -30.43 (STD-1) to $-18.98 \%$ o (PB-1), with the samples showing more depleted isotopic signatures. The unexpected value for the soft PVC PB-1 (-18.98\%o) was very far from the typical petrochemical isotopic signature. The $\delta^{13} \mathrm{C}$ value of $\mathrm{PB}-1$ can be explained by its plasticizer content, which can alter 
Table 1. Sample list of conventional plastics, biopolymer raw materials, bio-based plastics, and polymer blends

\begin{tabular}{|c|c|c|c|c|c|c|}
\hline Sample code & Material & Material class & Sample description & $\begin{array}{c}\text { Bio-based } \\
\text { content / \% }\end{array}$ & $\delta^{13} \mathrm{C}$ measured / \%o & Standard deviation \\
\hline STD-1 & petro-based HDPE & working standard & primary material (pellets) & $0^{\mathrm{a}}$ & -30.43 & 0.23 \\
\hline STD-2 & bio-based HDPE & working standard & primary material (pellets) & $>9^{\mathrm{a}}$ & -12.55 & 0.24 \\
\hline STD-3 & bio-based HDPE & working standard & primary material (pellets) & $>94^{\mathrm{a}}$ & -12.96 & 0.24 \\
\hline RM-1 & sugarcane sucrose & carbohydrate & powder & $100^{\mathrm{b}}$ & -10.68 & 0.21 \\
\hline RM-2 & ethanol & alcohol & liquid & $100^{\mathrm{b}}$ & -11.34 & 0.06 \\
\hline BB-1 & PLA & polymer & filament & $100^{\mathrm{b}}$ & -10.34 & 0.01 \\
\hline BB-2 & PLA & polymer & filament & $100^{\mathrm{b}}$ & -10.97 & 0.26 \\
\hline BB-3 & HDPE & polymer & pellets & $>94^{c}$ & -13.41 & 0.13 \\
\hline BB-4 & NR & polymer & rubber strip & $100^{c}$ & -27.72 & 0.10 \\
\hline M-1 & HDPE & polymer blend & package & $>92^{\mathrm{c}}$ & -12.97 & 0.03 \\
\hline M-2 & HDPE & polymer blend & package & $>85^{c}$ & -13.33 & 0.12 \\
\hline M-3 & HDPE & polymer blend & bag & $>90^{c}$ & -13.60 & 0.34 \\
\hline M-4 & HDPE & polymer blend & package & $>85^{\mathrm{c}}$ & -14.16 & 0.44 \\
\hline M-5 & HDPE & polymer blend & bag & $>92^{\mathrm{c}}$ & -14.28 & 0.51 \\
\hline M-6 & HDPE & polymer blend & bag & $>51^{\mathrm{c}}$ & -14.63 & 0.38 \\
\hline M-7 & HDPE & polymer blend & package & $>90^{c}$ & -16.45 & 0.17 \\
\hline M-8 & HDPE & polymer blend & bag & $>80^{c}$ & -16.87 & 0.02 \\
\hline M-9 & HDPE/LLDPE & polymer blend & package & $>80^{c}$ & -17.39 & 0.03 \\
\hline M-10 & HDPE & polymer blend & bag & $>80^{\circ}$ & -18.70 & 0.20 \\
\hline M-11 & HDPE & polymer blend & bag & $>80^{c}$ & -18.96 & 0.08 \\
\hline M-12 & HDPE & polymer blend & package & $>55^{\mathrm{c}}$ & -19.55 & 0.08 \\
\hline M-13 & PET/HDPE (1/4) & polymer blend & package & $>63^{c}$ & -19.62 & 0.13 \\
\hline M-14 & HDPE & polymer blend & package & $>55^{\mathrm{c}}$ & -22.95 & 0.34 \\
\hline M-15 & PET & polymer blend & bottle & $30^{c}(20)^{d}$ & -24.16 & 0.12 \\
\hline PB-1 & soft PVC & polymer & film & $0^{\mathrm{b}}$ & -18.98 & 0.03 \\
\hline PB-2 & $\mathrm{PVC}$ & polymer & pipe & $0^{\mathrm{b}}$ & -24.60 & 0.06 \\
\hline PB-3 & PP & polymer & pellets & $0^{\mathrm{b}}$ & -26.23 & 0.24 \\
\hline PB-4 & PET & polymer & bottle & $0^{\mathrm{b}}$ & -26.38 & 0.78 \\
\hline PB-5 & HDPE & polymer & package & $0^{\mathrm{b}}$ & -26.48 & 0.51 \\
\hline PB-6 & HDPE & polymer & package & $0^{\mathrm{b}}$ & -26.90 & 0.26 \\
\hline PB-7 & PP & polymer & package & $0^{\mathrm{b}}$ & -27.06 & 0.24 \\
\hline PB-8 & PS & polymer & package & $0^{\mathrm{b}}$ & -27.68 & 0.28 \\
\hline PB-9 & HDPE & polymer & bag & $0^{\mathrm{b}}$ & -27.83 & 0.12 \\
\hline PB-10 & LDPE & polymer & package & $0^{\mathrm{b}}$ & -27.86 & 1.44 \\
\hline PB-11 & HDPE & polymer & package & $0^{\mathrm{b}}$ & -27.98 & 0.15 \\
\hline PB-12 & HDPE & polymer & package & $0^{\mathrm{b}}$ & -28.48 & 0.23 \\
\hline PB-13 & PP & polymer & bottle cap & $0^{\mathrm{b}}$ & -28.66 & 0.19 \\
\hline PB-14 & PP & polymer & bottle cap & $0^{\mathrm{b}}$ & -30.14 & 1.32 \\
\hline
\end{tabular}

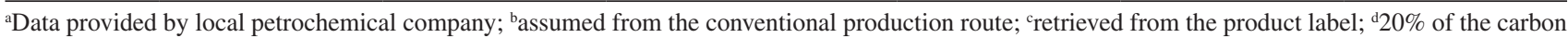
mass fraction, based on the structure of the polyethylene terephthalate monomer. STD: working standard calibrated against the certificate standard; RM: raw material; BB: bio-based; M: bio-based/petro-based blends; PB: petro-based; $\delta^{13} \mathrm{C}$ : carbon stable isotope data; HDPE: high density polyethylene; PLA: polylactic acid; NR: natural rubber; LDPE/LLDPE: low density polyethylene; PET: polyethylene terephthalate; PVC: polyvinyl chloride; PP: polypropylene; PS: polystyrene

the isotopic value of the polymer matrix when mixing carbon sources with different isotopic signatures.

Then, our results were compared with previously reported $\delta^{13} \mathrm{C}$ signatures of plastic materials and the data are shown in Table 2. From Table 2, it was identified that all results were similar to those previously reported

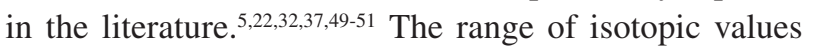

of plants are determined by other factors besides their photosynthetic cycle $\left(\mathrm{C}_{3}, \mathrm{C}_{4}\right.$ and Crassulacean acid metabolism (CAM)), including genetic, environmental (temperature and rainfall), and geographic (altitude and insolation) components. ${ }^{52-54}$ Thus, the differences between sugarcane sucrose (RM-1) and sugarcane ethanol (RM-2) are within the expected natural variations. ${ }^{48-50}$ Similarly, 
Table 2. $\delta^{13} \mathrm{C}$ values compared with previously reported data

\begin{tabular}{|c|c|c|c|c|c|}
\hline \multicolumn{3}{|c|}{ This work } & \multicolumn{3}{|c|}{ Literature } \\
\hline Material & Sample code & $\delta^{13} \mathrm{C}$ measured / \%o & Material & $\delta^{13} \mathrm{C}$ measured / \%o & Reference \\
\hline Ethanol & RM-2 & -11.34 & ethanol & -12.04 & 49 \\
\hline Bio-based PET (20\%) & M-15 & -24.16 & bio-based PET (20\%) & -24.34 & 22 \\
\hline PLA & BB-2 & -10.97 & PLA & -13.87 & 32 \\
\hline Sugarcane sucrose & RM-1 & -10.68 & sugarcane & -12.81 & 50 \\
\hline HDPE & STD-1 & -30.43 & PE powder (USGS77) & -30.71 & 51 \\
\hline HDPE & M-8 & -16.87 & bio-based PE & ca. -17.00 & 5 \\
\hline HDPE & STD-1 & -30.43 & primary material HD & -30.10 & 37 \\
\hline HDPE & STD-3 & -12.96 & $\begin{array}{c}\text { primary material } \\
\text { "environmentally-friendly" label }\end{array}$ & -13.50 & 37 \\
\hline
\end{tabular}

$\delta^{13} \mathrm{C}$ : carbon stable isotope data; PET: polyethylene terephthalate; PLA: polylactic acid; HD/HDPE: high density polyethylene; STD: working standard calibrated against the certificate standard; RM: raw material; BB: bio-based; M: bio-based/petro-based blends; PE: polyethylene.

petro-based HDPE (STD-1 $=-30.43 \%$ ) and sugarcanebased HDPE (STD-3 $=-12.96 \%$ ) gave similar isotopic values to the Santos et al. ${ }^{37}$ results for petro-based (primary material $\mathrm{HD}=-30.10 \%$ ) and sugarcane-based (primary material "environmentally-friendly" label $=-13.50 \%$ o) standards. On the other hand, the "bio-based PE", reported by Suzuki et al. ${ }^{5}$ had isotopic values significantly different from the bio-based HDPE pellets (STD-1, STD-2, and BB-3); however, it has a similar isotopic values to M-8 polymer blends. Thus, we can assume that the sample ("bio-based PE") was a bio-based/petro-based PE blend.

The $\delta^{13} \mathrm{C}$ value of the bio-based polyethylene pellets may vary slightly according to the product batch. Depending on the PE resin, the maximum bio-based content could change between LDPE (> 95\%), HDPE (> 94\%), and LLDPE (> 84\%). ${ }^{45}$ Differences in the polymerization process to obtain each resin grade, such as the use of comonomers of petrochemical origin (e.g., butene, hexene, and octene), can add carbon sources with a very different isotopic signature from sugarcane$\mathrm{PE}$ and reduce the biogenic fraction of the material $\left({ }^{14} \mathrm{C}\right.$ content) ${ }^{55}$ Furthermore, comparing the isotopic signature of the raw sugarcane-based HDPE (STD-2, STD-3, and $\mathrm{BB}-3$ ) and the ethanol $\delta^{13} \mathrm{C}$ value reported in the literature, also confirmed in the present study (RM-2), the dehydration of ethanol to form ethylene results in a lower isotopic fractionation when compared to other factors that influence the isotopic signature of the PE batch. ${ }^{48-50}$ In Figure 2, all $\delta^{13} \mathrm{C}$ results are summarized.

In Figure $2 \mathrm{a}$, all $\delta^{13} \mathrm{C}$ data is arranged according to the following classes: (i) standards, (ii) raw materials, (iii) bio-based, (iv) bio-based/petro-based blends, and (v) petro-based, while Figure $2 \mathrm{~b}$ shows the isotopic ratio ranges of each class found in this work. From Figure 2b, the raw material and bio-based polymers derived from $\mathrm{C}_{4}$ plants are clearly discriminated from the petro-based class, while the polymer blends had intermediate isotopic signatures. The NR (BB-6, derived from $\mathrm{C}_{3}$ plants) and the plasticized PVC (PB-1) samples were removed from Figure 2b, since they were not representative of bio-based polymers derived from $\mathrm{C}_{4}$ plants and petro-based materials, respectively.

Since industry uses ethanol derived from sugarcane as a raw material for bio-based polyethylene production, IRMS could easily discriminate PE from its origin, as
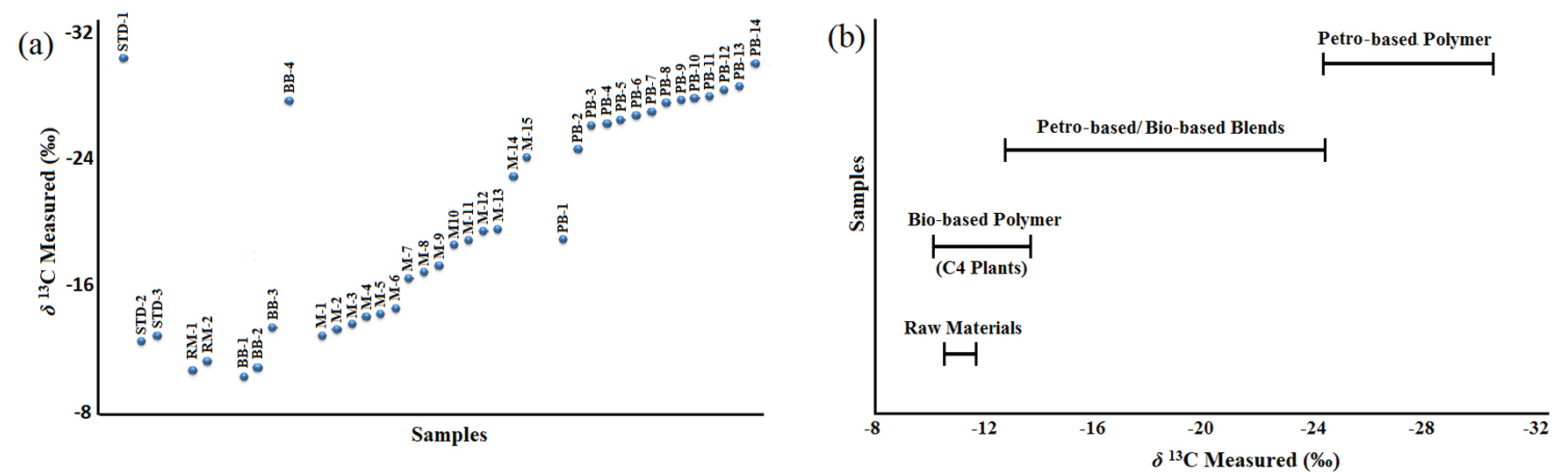

Figure 2. $\delta^{13} \mathrm{C}$ results for all samples including raw materials, bio-based polymers, bio-based/petro-based polymer blends, and petro-based polymers: (a) summary of the $\delta^{13} \mathrm{C}$ results and (b) isotope ratio range for the material classes. 
previously discussed by Suzuki et al..$^{5}$ Furthermore, there are differences in the $\delta^{13} \mathrm{C}$ composition of sugarcane and petroleum depending on their sources. ${ }^{48-50}$ From our results, we concluded that $\delta^{13} \mathrm{C}$ can be used to discriminate the origins of polymers (petro-based, sugarcane-based, or its blends), thus complementing the previous literature data. However, as the PE bio-based resins are generally sold blended with petro-based resins, there are still gaps on the potential application of stable isotope methods to estimate biogenic content or to serve as a screening tool in inspection chains.

\section{$\delta^{13} \mathrm{C}$ vs ${ }^{14} \mathrm{C}-\mathrm{AMS}$ regression}

The accreditation of biogenic content, despite its high cost, is a practice widely described and applied in the literature. . $10,14,20,25,26,37$ Thus, some results of the pMC determinations for materials derived from biomass and fossil sources are presented in Table 3 .

Table 3. Percent modern carbon (pMC) determination in bio-based and petro-based materials

\begin{tabular}{lccc}
\hline Material & Origin & $\mathrm{pMC}^{\mathrm{a}}$ \% & Reference \\
\hline Potato & bio-based & 100.1 & 20 \\
Rice & bio-based & 98.1 & 20 \\
Sugar beet & bio-based & 100.3 & 20 \\
Cellulose powder & bio-based & 110.9 & 14 \\
Corn & bio-based & 98.5 & 20 \\
Fructose & bio-based & 101.3 & 14 \\
Glucose & bio-based & 99.7 & 14 \\
Bio-based HDPE & bio-based & 97.7 & 25 \\
Bio-based polypropylene & bio-based & 106.7 & 2 \\
PLA & bio-based & 100 & 26 \\
Primary material & & & \\
"environmentally-friendly" & bio-based & 104.6 & 37 \\
label & & & \\
Gasoline & petro-based & $<0.1$ & 14 \\
PBS & petro-based & 0.3 & 10 \\
Primary material HD & petro-based & 0.0 & 37 \\
\hline
\end{tabular}

apMC estimated based on ASTM D6866. ${ }^{7}$ HD/HDPE: high density polyethylene; PLA: polylactic acid; PBS: poly(butylene succinate).

As can be observed, the bio-based materials have pMC values of approximately $100 \%$, which indicates that these materials are composed exclusively from modern sources of carbon. On the other hand, the petro-based materials have $\mathrm{pMC}$ values of approximately $0 \%$, which indicates that these materials come from fossil carbon sources. It has been previously reported in the literature ${ }^{14,56,57}$ that mixtures of bio-based and petro-based materials have intermediate
pMC values. Similarly, the same behavior was found for the $\delta^{13} \mathrm{C}$ isotopic values, in which the addition of a bio-based fraction resulted in a proportional change in the material $\delta^{13} \mathrm{C}$ isotopic signature. ${ }^{43,44}$ Therefore, it could be expected that a relationship between $\delta^{13} \mathrm{C}$ and ${ }^{14} \mathrm{C}$ could be found for sugarcane/petroleum polyethylene blends.

Before estimating the biogenic content of sugarcane/ petroleum PE blends by the $\delta^{13} \mathrm{C}$ method, it was necessary to carry out methodology validation to ensure its credibility. To validate the $\delta^{13} \mathrm{C}$ method, six points (STD-1, M-3, M-6, $\mathrm{M}-11, \mathrm{M}-12$, and M-14), covering the range between 0 and $98 \%$ of bio-based carbon percentage and stable isotope data $\left(\delta^{13} \mathrm{C}\right)$ from -30.43 to $-13.60 \%$, were sent for external ${ }^{14} \mathrm{C}$ analysis by AMS following the ASTM D6866 standard.? The results of ${ }^{14} \mathrm{C}$-AMS are shown in Table 4, while the relationship between the ${ }^{13} \mathrm{C}$ and ${ }^{14} \mathrm{C}$ data was evaluated by plotting the $\delta^{13} \mathrm{C}$ data against pMC values, and the results are presented in Figure 3.

Table 4. ${ }^{14} \mathrm{C}$-AMS analysis of bio-based/petro-based polyethylene blends

\begin{tabular}{lcccc}
\hline Sample code & $\delta^{13} \mathrm{C}^{\mathrm{a}} / \% 0$ & $\mathrm{pMC}, \mathrm{c} / \%$ & $\mathrm{BC}^{\mathrm{d}} / \%$ & $\mathrm{Label}^{\mathrm{e}} / \%$ \\
\hline M-3 & -13.60 & $99.05 \pm 3.00$ & $98 \pm 3$ & $>90$ \\
M-6 & -14.63 & $91.57 \pm 3.00$ & $91 \pm 3$ & $>51$ \\
M-11 & -18.96 & $63.99 \pm 3.00$ & $63 \pm 3$ & $>80$ \\
M-12 & -19.55 & $60.92 \pm 3.00$ & $60 \pm 3$ & $>55$ \\
M-14 & -22.95 & $17.93 \pm 3.00$ & $18 \pm 3$ & $>55$ \\
STD-1 & -30.43 & $<0.44 \pm 3.00$ & $0 \pm 3$ & NA \\
\hline
\end{tabular}

${ }^{\mathrm{a}} \delta^{13} \mathrm{C}$ values obtained by IRMS (this work); ${ }^{\mathrm{b}}{ }^{14} \mathrm{C}-\mathrm{AMS}$ analyzed at the Beta Analytic radiocarbon dating lab; ${ }^{58} \mathrm{pMC}$ : percentage of modern carbon;

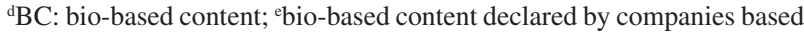
on ASTM D6866. $\delta^{13} \mathrm{C}$ : carbon stable isotope data; M: bio-based/petrobased blends; NA: not applied.

The present method directly relates the $\delta^{13} \mathrm{C}$ data to the biogenic content estimated by ${ }^{14} \mathrm{C}$-AMS. As the pMC content changes from 0 to $99.05 \%$, indicating an increase in the bio-based content of the PE blend, the $\delta^{13} \mathrm{C}$ value changes from -30.43 to $-13.60 \%$, with the intermediate $\delta^{13} \mathrm{C}$ values comprising the partial mixtures of sugarcane/ petroleum $\mathrm{PE}$, as proven by the ${ }^{14} \mathrm{C}-\mathrm{AMS}$ values. The scatter plot of $\delta^{13} \mathrm{C}$ versus $\mathrm{pMC}$ shows a relative adjusted linear relationship with a coefficient of determination $\left(\mathrm{R}^{2}\right)$ of 0.9373 . The M-14 sample, which had a value outside the estimated bio-based range, had a very large residual in relation to the regression (Figure 3a). When this sample was removed from the regression, the $\mathrm{R}^{2}$ value became 0.9983 (Figure 3b), which indicated a much more significant linear fit between $\delta^{13} \mathrm{C}$ and pMC. As previously reported by Taguchi et al., ${ }^{24,25}$ additives/fillers can modify the ${ }^{14} \mathrm{C}$-AMS results, since pMC is influenced by the 

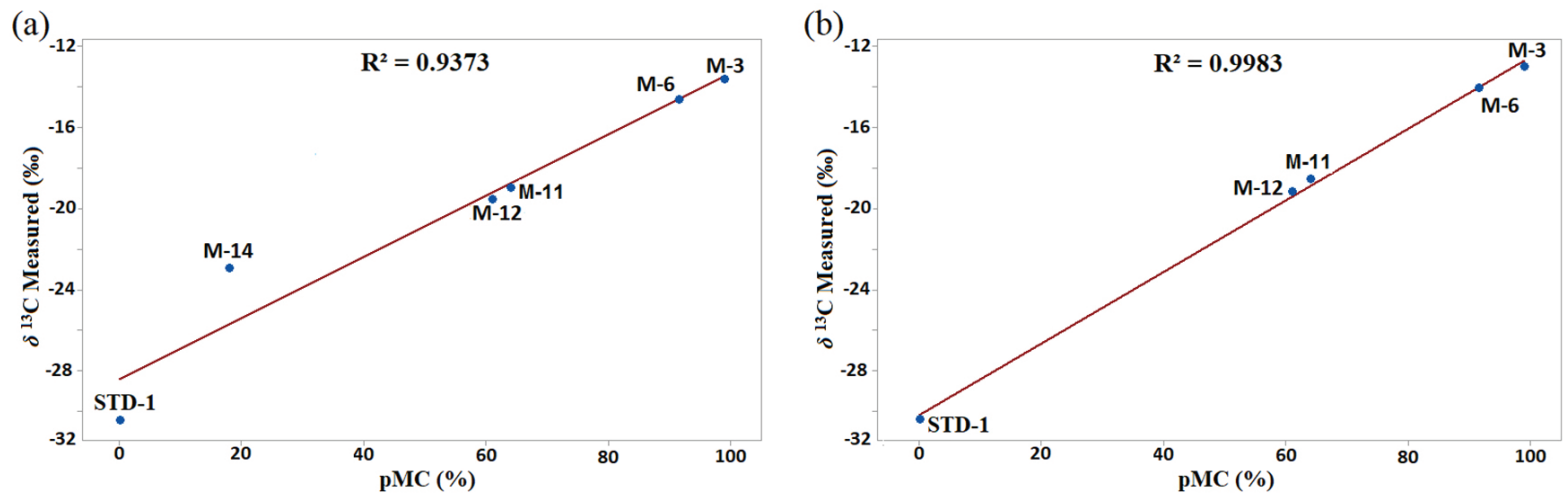

Figure 3. Scatter plot of $\delta^{13} \mathrm{C}$ versus pMC: (a) all samples and (b) with the outlier removed.

addition of other carbon sources. Therefore, it is expected that the stable isotope signatures would also be affected. Thus, the deviation of the M-14 sample could be related to the addition of other carbon sources (e.g., additives or fillers) to the polymer matrix. ${ }^{2,10,20,24,25}$ Thus, from the $\delta^{13} \mathrm{C}$ $v s{ }^{14} \mathrm{C}$-AMS regression, the biogenic content of sugarcane/ petroleum polyethylene blends can be estimated with reasonable reliability, since bio-based content data has been certified applying an international standard (ASTM D6866). ${ }^{7}$

\section{$\delta^{13} \mathrm{C}$ method}

The estimation of bio-based based content is generally performed by the ${ }^{14} \mathrm{C}$-AMS method; however, the low availability of certified centers to perform biogenic content accreditation exposes the fragility of product inspection chains. Once the relationship between $\delta^{13} \mathrm{C}$ and ${ }^{14} \mathrm{C}$ values were confirmed, the stable isotope data $\left(\delta^{13} \mathrm{C}\right)$ were used (i) to calibrate a regression model to estimate the biogenic content of sugarcane/petroleum polyethylene blends and (ii) to develop a screening model to identify samples suspected of being out of specification. Thus, in Figure 4, are presented: (i) the projection of the $\delta^{13} \mathrm{C}$ data of the sugarcane/petroleum polyethylene blends against biogenic content declared on the product labels (blue dots) and (ii) the regression lines relating the $\delta^{13} \mathrm{C}$ value with the biogenic content.

To estimate the biogenic content of sugarcane/petroleum polyethylene blends, a regression model was calibrated based on the $\delta^{13} \mathrm{C}$ data of STD-1 $\left(\delta^{13} \mathrm{C}=-30.43 \%\right.$ and $\mathrm{BC}=0 \%)$ and $\mathrm{M}-3\left(\delta^{13} \mathrm{C}=-13.60 \%\right.$ and $\left.\mathrm{BC}=98 \%\right)$ from the application of equation 6. The M-3 isotope data replace the $\delta^{13} \mathrm{C}_{\text {bio }}$ equation term, while the STD-1 isotope data replace the $\delta^{13} \mathrm{C}_{\text {perro }}$ term. The results of the $\delta^{13} \mathrm{C} v{ }^{14} \mathrm{C}$-AMS regression were compared with those obtained by the $\delta^{13} \mathrm{C}$ method. Thus, the calibrated models are shown in Figure 4a, while the predicted values for each of the samples are detailed in Table 5. For discussion purposes, samples characterized by ${ }^{14} \mathrm{C}$ (Table 4) will be used as a reference to assess the potential of regression models $\left(\delta^{13} \mathrm{C}\right.$ method and $\delta^{13} \mathrm{C} v s{ }^{14} \mathrm{C}$-AMS regression).
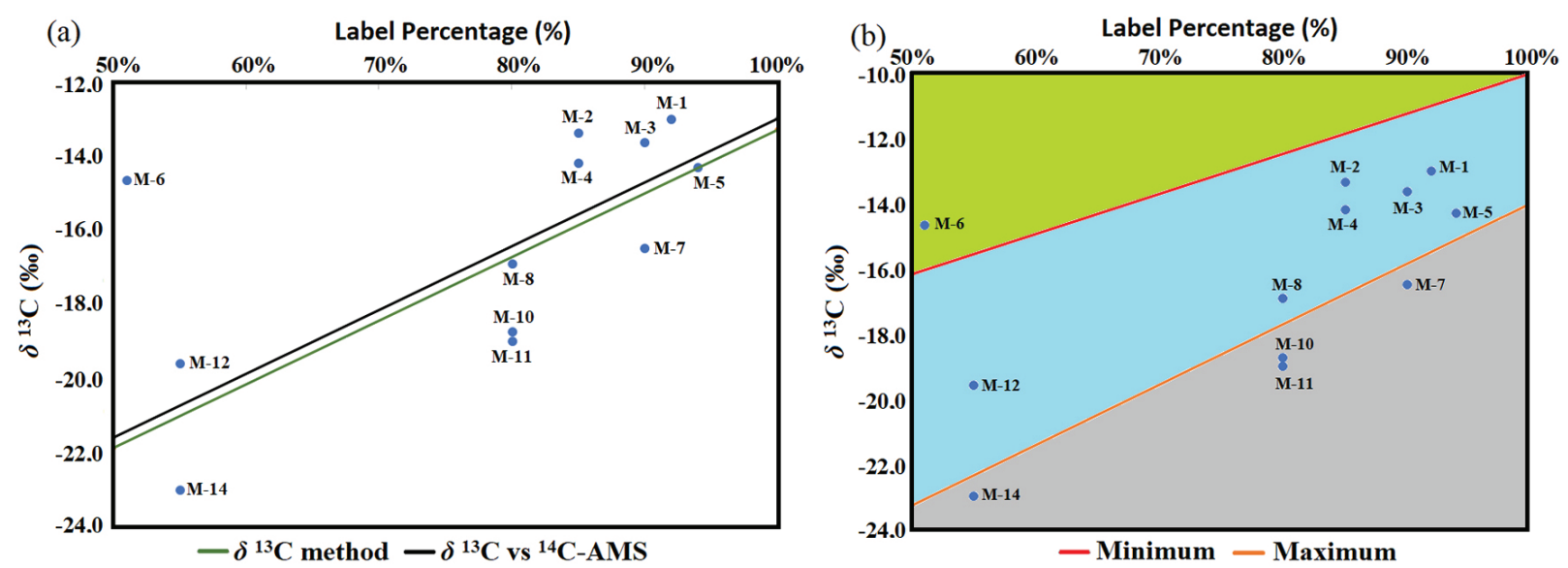

Figure 4. Projection of $\delta^{13} \mathrm{C}$ data versus biogenic content declared on the product label. (a) Scatter plot of $\delta^{13} \mathrm{C}$ versus biogenic content of PE polymer blends estimated by the $\delta^{13} \mathrm{C}$ method (green line) and by the $\delta^{13} \mathrm{C} v s{ }^{14} \mathrm{C}$-AMS regression (black line) and (b) maximum (orange line) and minimum (red line) bio-based content estimated by the $\delta^{13} \mathrm{C}$ data. Blue region: bio-based content is within the maximum and minimum estimated biogenic content; green region: bio-based content above the label-declared value; gray region: bio-based content below the label-declared value. 
Table 5. Bio-based content estimated from $\delta^{13} \mathrm{C}$ method and $\delta^{13} \mathrm{C} v s{ }^{14} \mathrm{C}$-AMS regression

\begin{tabular}{|c|c|c|c|c|}
\hline Sample code & $\delta^{13} \mathrm{C}^{\mathrm{a}} / \%$ & $\delta^{13} \mathrm{C}$ method BC $\mathrm{C}^{\mathrm{b}} / \%$ & $\delta^{13} \mathrm{C} v s^{14} \mathrm{CBC} / \%$ & Label $^{\mathrm{d}} / \%$ \\
\hline$\overline{M-1}$ & $-12.97 \pm 0.03$ & $101.7 \pm 0.2$ & $99.8 \pm 0.2$ & $>92$ \\
\hline M-2 & $-13.33 \pm 0.12$ & $99.6 \pm 0.7$ & $97.7 \pm 0.7$ & $>85$ \\
\hline M-3 & $-13.60 \pm 0.34$ & $98.0 \pm 2.0$ & $96.2 \pm 2.0$ & $>90$ \\
\hline M-4 & $-14.16 \pm 0.44$ & $94.7 \pm 2.6$ & $92.9 \pm 2.5$ & $>85$ \\
\hline M-5 & $-14.28 \pm 0.51$ & $94.0 \pm 3.0$ & $92.2 \pm 3.0$ & $>92$ \\
\hline M-6 & $-14.63 \pm 0.38$ & $92.0 \pm 2.2$ & $90.2 \pm 2.2$ & $>51$ \\
\hline M-7 & $-16.45 \pm 0.17$ & $81.4 \pm 1.0$ & $79.7 \pm 1.0$ & $>90$ \\
\hline M-8 & $-16.87 \pm 0.02$ & $79.0 \pm 0.1$ & $77.2 \pm 0.1$ & $>80$ \\
\hline M-10 & $-18.70 \pm 0.20$ & $68.3 \pm 1.2$ & $66.6 \pm 1.2$ & $>80$ \\
\hline M-11 & $-18.96 \pm 0.08$ & $66.8 \pm 0.5$ & $65.1 \pm 0.5$ & $>80$ \\
\hline M-12 & $-19.55 \pm 0.08$ & $63.4 \pm 0.5$ & $61.7 \pm 0.5$ & $>55$ \\
\hline M-14 & $-22.95 \pm 0.34$ & $43.6 \pm 2.0$ & $42.0 \pm 2.0$ & $>55$ \\
\hline
\end{tabular}

${ }^{a} \delta^{13} \mathrm{C}$ values obtained by IRMS (this work); bbio-based content estimation performed based on the $\delta^{13} \mathrm{C}$ method; cbio-based content estimated based on the $\delta^{13} \mathrm{C} v s{ }^{14} \mathrm{C}$-AMS regression; ${ }^{d}$ bio-based content declared by companies based on ASTM D6866. ${ }^{7} \delta^{13} \mathrm{C}$ : carbon stable isotope data; BC: bio-based content; M: bio-based/petro-based blends.

From Figure 4a and Table 5, it is observed that both models $\left(\delta^{13} \mathrm{C}\right.$ method and $\delta^{13} \mathrm{C} v s{ }^{14} \mathrm{C}$-AMS regression) presents similar results. When comparing the bio-based content estimated by the regression models $\left(\delta^{13} \mathrm{C}\right.$ method and $\delta^{13} \mathrm{C} v s{ }^{14} \mathrm{C}$-AMS regression), we found $100 \%$ agreement. Comparing the results with the ${ }^{14} \mathrm{C}$ bio-based contents (Table 4), it was found that $\mathrm{M}-3\left({ }^{14} \mathrm{C}=98 \%\right), \mathrm{M}-6$ $\left({ }^{14} \mathrm{C}=91 \%\right), \mathrm{M}-11\left({ }^{14} \mathrm{C}=63 \%\right)$ and $\mathrm{M}-12\left({ }^{14} \mathrm{C}=60 \%\right)$ were within the estimated range obtained from the $\delta^{13} \mathrm{C}$ method $(\mathrm{M}-3=98.0 \%$; M-6 $=92.0 \% ; \mathrm{M}-11=66.8 \%$ and $\mathrm{M}-12=63.4 \%)$ and $\delta^{13} \mathrm{C} v s{ }^{14} \mathrm{C}$-AMS regression $(\mathrm{M}-3=96.2 \% ; \mathrm{M}-6=90.2 \% ; \mathrm{M}-11=65.1 \%$ and $\mathrm{M}-12=61.7 \%)$. On the other hand, the M-14 was found to contain $18 \%$ biogenic fraction by the ${ }^{14} \mathrm{C}$-AMS and was significantly lower than estimated by the $\delta^{13} \mathrm{C}$ method (43.6\%) and by the $\delta^{13} \mathrm{C} v s{ }^{14} \mathrm{C}$-AMS regression $(42.0 \%)$. As previously discussed, the deviation of the M-14 sample could be related to the addition of other carbon sources (e.g., additives or fillers) to the polymer matrix. ${ }^{2,10,20,24,25} \mathrm{In}$ addition, the bio-based content of sample $\mathrm{M}-14\left({ }^{14} \mathrm{C}=18 \%\right)$ is very far from the minimum range of biogenic content required for the use of "environmentally-friendly" label $(\geq 51 \%)$, which can also contribute to the significant deviation in estimated values. However, all methods $\left(\delta^{13} \mathrm{C}\right.$ and ${ }^{14} \mathrm{C}$-AMS) agreed in that the bio-based content of M-14 was below the label-declared value (>55\%). Thus, from these results, an $80 \%$ accuracy rate was obtained when comparing the biogenic content estimated by $\delta^{13} \mathrm{C}$ and ${ }^{14} \mathrm{C}$-AMS analysis.

Furthermore, a screening model was proposed combining: (i) the projection of the $\delta^{13} \mathrm{C}$ data of sugarcane/ petroleum polyethylene blends against the biogenic content declared on the product labels and (ii) the delimitation of a specification zone, considering the wide natural variation of the stable isotope value of derivatives of petroleum and $\mathrm{C}_{4}$ plants. The limits (minimum and maximum) were estimated based on equation 6 , considering the natural isotopic variation of $\mathrm{C}_{4}$ plants (from -10.0 to $-14.0 \%$ ) and crude oil (from -23.3 to $-32.5 \%$ ) ${ }^{46,47}$ Thus, by replacing the $\delta^{13} \mathrm{C}_{\text {petro }}$ and $\delta^{13} \mathrm{C}_{\text {bio }}$ terms of equation 6 with the isotope values from the literature, it is possible to estimate the minimum (red line) and maximum (orange line) biogenic content expected for an unknown sample. The results are presented in the Figure $4 \mathrm{~b}$, while the minimum and maximum biogenic content of an unknown sample are presented in Table 6 .

From Figure $4 \mathrm{~b}$, three regions are highlighted in the specification zone, comprising: (i) the green region, representing the area where the sample bio-based content was above the label-declared value, (ii) the blue region, representing the area where the sample bio-based content was within the maximum and minimum regression borders and (iii) the grey region, representing the area where the sample bio-based content was below the label-declared value.

Comparing the data in Tables 4 and 6 and Figure 4, the ${ }^{14} \mathrm{C}$-AMS analysis validates $100 \%$ of the IRMS results in relation to the evaluation of the product label. The samples $\mathrm{M}-3\left({ }^{14} \mathrm{C}=98 \% ; \delta^{13} \mathrm{C}=70.7\right.$ to $\left.102.2 \%\right)$ and $\mathrm{M}-12\left({ }^{14} \mathrm{C}=60 \% ; \delta^{13} \mathrm{C}=22.4\right.$ to $\left.70.0 \%\right)$, plotted in the blue region, had bio-based contents slightly above the label-declared value (M-3 > 90\% and $\mathrm{M}-12>55 \%)$. These samples meet consumer expectations and conform 
Table 6. Maximum and minimum bio-based content estimated from $\delta^{13} \mathrm{C}$ data

\begin{tabular}{|c|c|c|c|c|}
\hline Sample code & $\delta^{13} \mathrm{C}^{\mathrm{a}} / \%$ & $\mathrm{Min}^{\mathrm{b}} \mathrm{BC} / \%$ & $\mathrm{Max}^{\mathrm{b}} \mathrm{BC} / \%$ & Label $^{\mathrm{c}} / \%$ \\
\hline M-1 & $-12.97 \pm 0.03$ & $75.9 \pm 0.2$ & $105.6 \pm 0.2$ & $>92$ \\
\hline $\mathrm{M}-2$ & $-13.33 \pm 0.12$ & $72.9 \pm 1.0$ & $103.6 \pm 0.6$ & $>85$ \\
\hline M-3 & $-13.60 \pm 0.34$ & $70.7 \pm 2.8$ & $102.2 \pm 1.8$ & $>90$ \\
\hline M-4 & $-14.16 \pm 0.44$ & $66.2 \pm 3.6$ & $99.1 \pm 2.4$ & $>85$ \\
\hline M-5 & $-14.28 \pm 0.51$ & $65.2 \pm 4.2$ & $98.5 \pm 2.8$ & $>92$ \\
\hline M-6 & $-14.63 \pm 0.38$ & $62.4 \pm 3.1$ & $96.6 \pm 2.1$ & $>51$ \\
\hline M-7 & $-16.45 \pm 0.17$ & $47.6 \pm 1.4$ & $86.8 \pm 0.9$ & $>90$ \\
\hline M-8 & $-16.87 \pm 0.02$ & $44.1 \pm 0.2$ & $84.5 \pm 0.1$ & $>80$ \\
\hline M-10 & $-18.70 \pm 0.20$ & $29.3 \pm 1.6$ & $74.6 \pm 1.1$ & $>80$ \\
\hline M-11 & $-18.96 \pm 0.08$ & $27.2 \pm 0.7$ & $73.2 \pm 0.4$ & $>80$ \\
\hline M-12 & $-19.55 \pm 0.08$ & $22.4 \pm 0.7$ & $70.0 \pm 0.4$ & $>55$ \\
\hline M-14 & $-22.95 \pm 0.34$ & $-5.3 \pm 2.8$ & $51.6 \pm 1.8$ & $>55$ \\
\hline
\end{tabular}

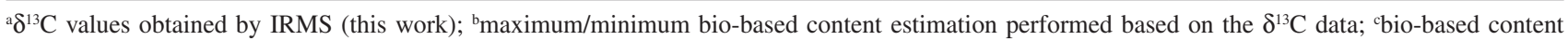
declared by companies based on ASTM D6866.7 $\delta^{13} \mathrm{C}$ : carbon stable isotope data; BC: bio-based content; M: bio-based/petro-based blends.

to the image desired by the company when adopting the "environmentally-friendly" label. In addition, the sample M-6 $\left({ }^{14} \mathrm{C}=91 \% ; \delta^{13} \mathrm{C}=62.4\right.$ to $\left.96.6 \%\right)$, plotted in the green region, had a bio-based content above the labeldeclared value $(>51 \%)$. This difference is not detrimental for the consumers; however, represents a waste of financial resources for the company, because more bio-based resin was added than declared by the label. Otherwise, the samples $\mathrm{M}-11\left({ }^{14} \mathrm{C}=63 \% ; \delta^{13} \mathrm{C}=27.2\right.$ to $\left.73.2 \%\right)$ and $\mathrm{M}-14$ $\left({ }^{14} \mathrm{C}=18 \% ; \delta^{13} \mathrm{C}=-5.3\right.$ to $\left.51.6 \%\right)$, plotted in the grey region, had bio-based contents below the label-declared value (M-11 > 80\% and M-14 > 55\%). These samples did not conform to the information presented on the company label; they represented a misuse of the "environmentallyfriendly" label and deceived consumers. Therefore, based on the biogenic content estimated by $\delta^{13} \mathrm{C}$, and supported by ${ }^{14} \mathrm{C}$-AMS results, $33.33 \%$ of the samples plotted in the Figure $4 \mathrm{~b}$ are suspected of being out of specification.

From the screening method, it was possible to identify samples most likely to be out of specification and reduce the demand for inspection of biogenic content following the ASTM D6866 standard $\left({ }^{14} \mathrm{C}-\mathrm{AMS}\right) .{ }^{7}$ In future work, the variability of the isotopic signature of sugarcane-based and petro-based PE must be evaluated, to calibrate the most specified model for the analysis of sugarcane/petroleum polyethylene blends.

\section{Conclusions}

In the present work, we propose the application of stable isotope analysis $\left(\delta^{13} \mathrm{C}\right)$ as an auxiliary tool for the inspection of sugarcane/petroleum polyethylene blends. Thus, the potential and limitations of $\delta^{13} \mathrm{C}$ data for: (i) discriminate the origins of the samples, (ii) calibrate regression models to estimate the biogenic content of sugarcane/petroleum polyethylene blends and (iii) develop a screening model to identify samples most likely to be out of specification, were evaluated. Our results are supported from the analysis of selected samples by accelerator mass spectrometry $\left({ }^{14} \mathrm{C}\right.$-AMS), following the ASTM D6866 standard.

From our results, it was concluded that the $\delta^{13} \mathrm{C}$ method is suitable to discriminate the samples derived from sugarcane, petroleum, or its blends. It was also observed that the stable isotope data $\left(\delta^{13} \mathrm{C}\right)$ had almost a linear relationship with pMC $\left({ }^{14} \mathrm{C}-\mathrm{AMS}\right)$. Thus, from the regression models $\left(\delta^{13} \mathrm{C}\right.$ method and $\delta^{13} \mathrm{C}$ vs ${ }^{14} \mathrm{C}$-AMS regression), we conclude that the stable isotope data show potential to estimate the biogenic content of sugarcane/petroleum PE blends. When comparing the biogenic content estimated by the $\delta^{13} \mathrm{C}$ method with the $\delta^{13} \mathrm{C} v{ }^{14} \mathrm{C}$-AMS regression results, we found $100 \%$ agreement between models. In addition, when comparing the biogenic content estimated by $\delta^{13} \mathrm{C}$ models ( $\delta^{13} \mathrm{C}$ method and $\delta^{13} \mathrm{C} v s{ }^{14} \mathrm{C}$-AMS regression) with the ${ }^{14} \mathrm{C}$-AMS results, we found an accuracy rate of $80 \%$. Despite the identified potential, future work should focus on validating the regression models $\left(\delta^{13} \mathrm{C}\right.$ method and $\delta^{13} \mathrm{C}$ vs ${ }^{14} \mathrm{C}$-AMS regression).

Furthermore, a screening method was proposed combining: ( $i$ ) the projection of the $\delta^{13} \mathrm{C}$ data of sugarcane/ petroleum polyethylene blends against the biogenic content declared on the product labels and (ii) the delimitation of a specification zone, considering the wide natural variation of the stable isotope value of derivatives of petroleum and $\mathrm{C}_{4}$ plants. Based on the screening model developed with 
$\delta^{13} \mathrm{C}$ data, and supported by ${ }^{14} \mathrm{C}$-AMS results, $33.33 \%$ of the samples were suspected of being out of specification. From our results, we conclude that the screening method can identify samples most likely to be out of specification and reduce the demand for inspection of biogenic content following the ASTM D6866 standard $\left({ }^{14} \mathrm{C}-\mathrm{AMS}\right)$. These results highlight the fragility in the product inspection chain, the misuse of the "environmentally-friendly" label, and a detriment to the consumer. In future work, the variability of the isotopic signature of sugarcane-based and petro-based PE must be evaluated, to calibrate the most specified model for the analysis of sugarcane/petroleum polyethylene blends.

The stable carbon isotope method does not replace accreditation in accordance with ASTM D6866; however, even with the radiocarbon isotope (ASTM D6866) being the recognized standard, the present work demonstrates that $\delta^{13} \mathrm{C}$ could be applied as an auxiliary tool for the inspection of sugarcane/petroleum PE blends available in the Brazilian market. From the proposed approach, it was possible to identify a perspective on the application of stable isotope data $\left(\delta^{13} \mathrm{C}\right)$ to: (i) estimate biogenic content (regression methods) and (ii) identify samples suspected of being out of specification (screening method). Due to the natural variability of the isotopic signature of the raw polyethylene (sugarcane-based and petro-based), future works should broaden the scope of this work to: $(i)$ take into account the natural variability in the isotopic ratio of sugarcane and petrochemical polyethylene and (ii) validate the proposed models (screening and regression methods) from a representative sampling of sugarcane/petroleum polyethylene blends. In this way, it will be possible to develop the most specified model for the quality assurance of sugarcane/petroleum polyethylene blends.

\section{Acknowledgments}

The authors thank Dra Carmen Iara Walter Calcagno of the Instituto Federal de Educação, Ciência e Tecnologia Sul-Rio-Grandense (IFSUL), Campus Sapucaia do Sul for donating the raw HDPE pellets and the Institute of Petroleum and Natural Resources (IPR) of the Pontifical Catholic University of Rio Grande do Sul for the use of infrastructure.

\section{References}

1. North, E. J.; Halden, R. U.; Rev. Environ. Health 2013, $28,1$.

2. Funabashi, M.; Ohara, K.; Kunioka, M.; Polym. Degrad. Stab. 2014, 109, 385.
3. https://www.plasticseurope.org/application/ files/4315/1310/4805/plastic-the-fact-2016.pdf, accessed in July 2020.

4. Morschbacker, A.; Polym. Rev. 2009, 49, 79.

5. Suzuki, Y.; Akamatsu, F.; Nakashita, R.; Korenaga, T.; Chem. Lett. 2010, 39, 998.

6. Papong, S.; Malakul, P.; Trungkavashirakun, R.; Wenunun, P.; Chom-in, T.; Nithitanakul, M.; Sarobol, E.; J. Cleaner Prod. 2014, 65, 539.

7. ASTM D6866: Standard Test Methods for Determining the Biobased Content of Solid, Liquid, and Gaseous Samples Using Radiocarbon Analysis, ASTM International, West Conshohocken, PA, 2020.

8. Mulinari, D. R.; Voorwald, H. J. C.; Cioffi, M. O. H.; Silva, M. L. C. P.; Luz, S. M.; Carbohydr. Polym. 2009, 75, 317.

9. Mooney, B. P.; Biochem. J. 2009, 418, 219.

10. Funabashi, M.; Ninomiya, F.; Flores, E. D.; Kunioka, M.; J. Polym. Environ. 2010, 18, 85.

11. Iwata, T.; Angew. Chem., Int. Ed. 2015, 54, 3210.

12. Tsiropoulos, I.; Faaij, A. P. C.; Lundquist, L.; Schenker, U.; Briois, J. F.; Patel, M. K.; J. Cleaner Prod. 2015, 90, 114.

13. https://docs.european-bioplastics.org/publications/market_ data/2017/Report_Bioplastics_Market_Data_2017.pdf, accessed in July 2020.

14. Kunioka, M.; Appl. Microbiol. Biotechnol. 2010, 87, 491.

15. Alvarenga, R. A. F.; Dewulf, J.; Renewable Energy 2013, 59, 49.

16. Liptow, C.; Tillman, A. M.; J. Ind. Ecol. 2012, 16, 420.

17. Alvarenga, R. A.; Dewulf, J.; de Meester, S.; Wathelet, A.; Villers, J.; Thommeret, R.; Hruska, Z.; Biofuels, Bioprod. Biorefin. 2013, 7, 386.

18. de Andrade Coutinho, P. L.; Morita, A. T.; Cassinelli, L. F.; Morschbacker, A.; Werneck do Carmo, R. In Catalytic Process Development for Renewable Materials; Imhof, P.; van der Waal, J. C., eds.; Wiley-VCH Verlag GmbH \& Co. KGaA: Weinheim, Germany, 2013, ch. 6.

19. Belboom, S.; Léonard, A.; Biomass Bioenergy 2016, 85, 159.

20. Kunioka, M.; Ninomiya, F.; Funabashi, M.; J. Polym. Environ. 2007, 15, 281.

21. Norton, G. A.; Devlin, S. L.; Bioresour. Technol. 2006, 97, 2084.

22. Jou, R. M.; Macario, K. D.; Carvalho, C.; Dias, R. S.; Brum, M. C.; Cunha, F. R.; Ferreira, C. G.; Chanca, I. S.; Int. J. Mass Spectrom. 2015, 388, 65.

23. Macario, K. D.; Oliveira, F. M.; Carvalho, C.; Santos, G. M.; Xu, X.; Chanca, I. S.; Alves, E. Q.; Jou, R. M.; Oliveira, M. I.; Pereira, B. B.; Moreira, V.; Muniz, M. C.; Linares, R.; Gomes, P. R. S.; dos Anjos, R. M.; Castro, M. D.; dos Anjos, L.; Marques, A. N.; Rodrigues, L. F.; Nucl. Instrum. Methods Phys. Res., Sect. B 2015, 361, 402.

24. Taguchi, K.; Kunioka, M.; Funabashi, M.; Ninomiya, F.; J. Appl. Polym. Sci. 2014, 131, 39978. 
25. Taguchi, K.; Kunioka, M.; Funabashi, M.; Ninomiya, F.; SpringerPlus 2014, 3, 6.

26. Onishi, T.; Ninomiya, F.; Kunioka, M.; Funabashi, M.; Ohara, K.; Polym. Degrad. Stab. 2010, 95, 1276.

27. Nagakawa, Y.; Yunoki, S.; Saito, M.; Polym. Test. 2014, 33, 13.

28. Idoine, F. A.; Carter, J. F.; Sleeman, R.; Rapid Commun. Mass Spectrom. 2005, 19, 3207.

29. Muccio, Z.; Jackson, G. P.; Analyst 2009, 134, 213.

30. Coplen, T. B.; Brand, W. A.; Gehre, M.; Gröning, M.; Meijer, H. A. J.; Toman, B.; Verkouteren, R. M.; Anal. Chem. 2006, 78, 2439.

31. Gilbert, A.; Hattori, R.; Silvestre, V.; Wasano, N.; Akoka, S.; Hirano, S.; Yamada, K.; Yoshida, N.; Remaud, G. S.; Talanta 2012, 99, 1035.

32. Berto, D.; Rampazzo, F.; Gion, C.; Noventa, S.; Ronchi, F.; Traldi, U.; Giorgi, G.; Cicero, A. M.; Giovanardi, O.; Chemosphere 2017, 176, 47.

33. Carter, J. F.; Grundy, P. L.; Hill, J. C.; Ronan, N. C.; Titterton, E. L.; Sleeman, R.; Analyst 2004, 129, 1206.

34. Horacek, M.; Min, J. S.; Heo, S.; Park, J.; Papesch, W.; Rapid Commun. Mass Spectrom. 2008, 22, 1763.

35. Taylor, E.; Carter, J. F.; Hill, J. C.; Morton, C.; Daeid, N. N.; Sleeman, R.; Forensic Sci. Int. 2008, 177, 214.

36. Suzuki, Y.; Kobe, R.; Nakashita, R.; Chem. Lett. 2012, 41, 242.

37. Santos, J. F. P.; Macario, K. D.; Jou, R. M.; Oliveira, F. M.; Cardoso, R. P.; Diaz, M.; Anjos, R. M.; Alves, E. Q.; J. Cleaner Prod. 2019, 233, 348.

38. Iles, A.; Martin, A. N.; J. Cleaner Prod. 2013, 45, 38.

39. http://www.braskem.com.br/Portal/Principal/Arquivos/ ModuloHTML/Documentos/1069/I_m_green_ Communication_Guide.pdf, accessed in May 2020.

40. dos Santos, V. H. J. M.; Ramos, A. S.; Pires, J. P.; Engelmann, P. M.; Lourega, R. V.; Ketzer, J. M. M.; Rodrigues, L. F.; Chemom. Intell. Lab. Syst. 2017, 161, 70.

41. dos Santos, V. H. J. M.; Ketzer, J. M. M.; Rodrigues, L. F.; Energy Fuels 2017, 31, 523.

42. Dunn, P. J. H.; Carter, J. F.; Good Practice Guide for Isotope Ratio Mass Spectrometry, $2^{\text {nd }}$ ed.; FIRMS: UK, 2018.

43. Cerri, C. E. P.; Paustian, K.; Bernoux, M.; Victoria, R. L.; Melillo, J. M.; Carlos, C.; GCB Bioenergy 2004, 10, 815.
44. Franco, A. L. C.; Cherubin, M. R.; Pavinato, P. S.; Cerri, C. E. P.; Six, J.; Davies, C. A.; Cerri, C. C.; Sci. Total Environ. 2015, 515,30

45. http://plasticoverde.braskem.com.br/Portal/Principal/Arquivos/ ModuloHTML/Documentos/1344/Catalogo-PE-VERDEING_Feria_digital_simples.pdf, accessed in July 2020.

46. Yeh, H. W.; Epstein, S.; Geochim. Cosmochim. Acta 1981, 45, 753.

47. Cerling, T. E.; Wang, Y.; Quade, J.; Nature 1993, 361, 344.

48. Neves, L. A.; Sarmanho, G. F.; Cunha, V. S.; Daroda, R. J.; Aranda, D. A. G. G.; Eberlin, M. N.; Fasciotti, M.; Anal. Methods 2015, 7, 4780.

49. Silva, G. C.; Moreira, M. Z.; Scofield, A. L.; Godoy, J. M. O. O.; Almeida, L. F.; Wagener, A. L. R. R.; J. Braz. Chem. Soc. 2015, 26, 1283.

50. Ishida-Fujii, K.; Goto, S.; Uemura, R.; Yamada, K.; Sato, M.; Yoshida, N.; Biosci., Biotechnol., Biochem. 2005, 69, 2193.

51. Schimmelmann, A.; Qi, H.; Coplen, T. B.; Brand, W. A.; Fong, J.; Meier-Augenstein, W.; Kemp, H. F.; Toman, B.; Ackermann, A.; Assonov, S.; Aerts-Bijma, A. T.; Brejcha, R.; Chikaraishi, Y.; Darwish, T.; Elsner, M.; Gehre, M.; Geilmann, H.; Gröning, M.; Hélie, J.-F.; Herrero-Martín, S.; Meijer, H. A. J. J.; Sauer, P. E.; Sessions, A. L.; Werner, R. A.; Anal. Chem. 2016, 88, 4294.

52. O'Leary, M. H.; Phytochemistry 1981, 20, 553.

53. Farquhar, G. D.; Ehleringer, J. R.; Hubick, K. T.; Annu. Rev. Plant Physiol. Plant Mol. Biol. 1989, 40, 503.

54. Tieszen, L. L.; J. Archaeol. Sci. 1991, 18, 227.

55. Morris, B. A. The Science and Technology of Flexible Packaging: Multilayer Films from Resin and Process to End Use, $1^{\text {st }}$ ed.; William Andrew: Norwich, USA, 2016.

56. Norton, G. A.; Hood, D. G.; Devlin, S. L.; Bioresour. Technol. 2007, 98, 1052.

57. Quarta, G.; Calcagnile, L.; Giffoni, M.; Braione, E.; D’Elia, M.; Radiocarbon 2013, 55, 1834.

58. www.radiocarbon.com, accessed in July 2020.

Submitted: April 4, 2020

Published online: July 30, 2020 